\title{
$N F-\kappa B$ activation in inflammatory breast cancer is associated with oestrogen receptor downregulation, secondary to EGFR and/or ErbB2 overexpression and MAPK hyperactivation
}

\author{
SJ Van Laere', I Van der Auwera', GG Van den Eynden', P van Dam', EA Van Marck', PB Vermeulen*,I and \\ LY Dirix'
}

'Translational Cancer Research Group, Lab Pathology University of Antwerp, Universiteitsplein I and Oncology Center, General Hospital Sint-Augustinus, Oosterveldlaan 24, Wilrijk B2610, Belgium

\begin{abstract}
Activation of NF- $\mathrm{KB}$ in inflammatory breast cancer (IBC) is associated with loss of estrogen receptor (ER) expression, indicating a potential crosstalk between NF- $\mathrm{KB}$ and ER. In this study, we examined the activation of NF- $\mathrm{KB}$ in IBC and non-IBC with respect to ER and EGFR and/or ErbB2 expression and MAPK hyperactivation. A qRT-PCR based ER signature was evaluated in tumours with and

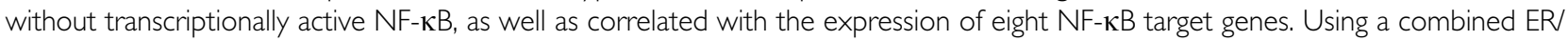
NF- $\kappa B$ signature, hierarchical clustering was executed. Hyperactivation of MAPK was investigated using a recently described MAPK signature (Creighton et al, 2006), and was linked to tumour phenotype, ER and EGFR and/or ErbB2 overexpression. The expression of most ER-modulated genes was significantly elevated in breast tumours without transcriptionally active NF- $\kappa \mathrm{B}$. In addition, the expression of most ER-modulated genes was significantly anticorrelated with the expression of most NF- $\kappa \mathrm{B}$ target genes, indicating

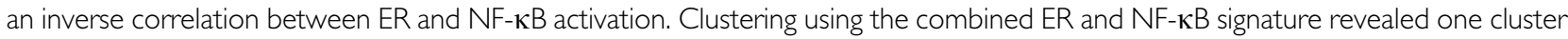

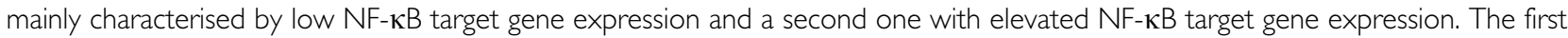
cluster was mainly characterised by non-IBC specimens and IHC ER + breast tumours ( 13 out of I 8 and I5 out of I 8 respectively), whereas the second cluster was mainly characterised by IBC specimens and IHC ER- breast tumours ( 12 out of 19 and I5 out of 19 respectively) (Pearson $\chi^{2}, P<0.000 \mathrm{I}$ and $P<0.000 \mathrm{I}$ respectively). Hyperactivation of MAPK was associated with both ER status and tumour phenotype by unsupervised hierarchical clustering using the MAPK signature and was significantly reflected by overexpression of EGFR and/or ErbB2. NF- $\kappa B$ activation is linked to loss of ER expression and activation in IBC and in breast cancer in general. The inverse correlation between NF- $\kappa \mathrm{B}$ activation and ER activation is due to EGFR and/or ErbB2 overexpression, resulting in NF- $\kappa \mathrm{B}$ activation and ER downregulation.

British Journal of Cancer (2007) 97, 659-669. doi:I0.1038/sj.bjc.6603906 www.bjcancer.com

Published online 14 August 2007

(c) 2007 Cancer Research UK
\end{abstract}

Keywords: inflammatory breast cancer; NF- $\kappa$ B; oestrogen receptor; mitogen-activated protein kinase; EGFR; ErbB2

Breast cancer is the most frequent cause of cancer death in women worldwide (Key et al, 2001) and represents the second leading cause of cancer death among women in the United States (National Center for Chronic Disease Prevention and Health Promotion, 2006) (Key et al, 2001; Dumitrescu and Cotarla, 2005; Draper, 2006). Inflammatory Breast Cancer (IBC) is a distinct clinical subtype of locally advanced breast cancer (LABC), with a particularly aggressive behaviour and poor prognosis. Clinically, IBC typically presents with rapidly progressive breast erythema, warmth, oedema and induration (Haagensen, 1956 , p. 488). At the time of diagnosis, most patients have axillary lymph node involvement and 1 out of 3 patients have metastasis in distant organs (Kleer et al, 2000; Lerebours et al, 2005). The characteristic pathology is the invasion of dermal

*Correspondence: Dr PB Vermeulen,

E-mail: Peter.Vermeulen@GZA.be

Received I 5 January 2007; revised 25 June 2007; accepted 28 June 2007; published online 14 August 2007 lymphatics by tumour emboli, however, this is only present in $50-$ $75 \%$ of the cases (Kleer et al, 2000; Low et al, 2004; Lerebours et al, 2005). Hence, IBC is primarily a clinical diagnosis classified as T4d in the TNM classification of the American Joint Committee on Cancer (Singletary et al, 2002). Despite advances in multidisciplinary treatment, the prognosis of IBC is less favourable than of non-IBC, with a 3 -year survival of about $40 \%$ (Lerebours et al, 2005).

Recently, both in vitro and in vivo experiments have indicated that the biology of IBC has some important differences with the biology of other breast carcinomas. Overexpression of the RhoC GTPase (Van Golen et al, 1999; Van Golen, 2003; Kleer et al, 2004; Van den Eynden et al, 2004) and loss of WISP3 protein expression (Van Golen et al, 1999; Kleer et al, 2004) are highly correlated with the IBC phenotype. It has been demonstrated that overexpression of the RhoC GTPase is directly and specifically implicated in the production of angiogenic factors by IBC cells (Van Golen et al, 2000). In human samples, increased angiogenesis in IBC was evident by both an increased number of microvessels and a higher 
fraction of proliferating endothelial cells (Colpaert et al, 2003), as well as increased expression of several angiogenic growth factors and growth factor receptors in IBC compared to non-IBC (Van der Auwera et al, 2004). The specific biology of IBC was further demonstrated by the fact that a molecular signature based on the differential expression of 756 genes is able to separate IBC from non-IBC in an unsupervised hierarchical clustering analysis. The 756 genes-based molecular signature was subjected to a detailed analysis, revealing the presence of several NF- $\kappa \mathrm{B}$ target genes and upstream activators of the NF- $\kappa \mathrm{B}$ signalling pathway, with strong expression in IBC as compared to non-IBC (Van Laere et al, 2005). The NF- $\kappa B$ signature has been validated using qRT-PCR for $\mathrm{NF}-\kappa \mathrm{B}$ target genes and immunohistochemistry and NF- $\kappa \mathrm{B}$ DNA-binding experiments for different NF- $\mathrm{BB}$ transcription factors (Van Laere et al, 2006b).

The activation of NF- $\mathrm{BB}$ in breast cancer has been extensively described in oestrogen receptor negative $(\mathrm{ER}-)$ breast tumours and ER - breast cancer cell lines suggesting an important inhibitory crosstalk between both signalling pathways (Biswas et al, 2000, 2001, 2004; Zhou et al, 2005). This inhibitory cross-talk can be appreciated from the fact that an increase in both NF- $\kappa \mathrm{B}$ DNA-binding activity (Nakshatri et al, 1997; Pratt et al, 2003) and expression of NF- $\mathrm{BB}$ target genes like IL8 (Freund et al, 2004) coincides with a shift from oestrogen dependence to oestrogen independence in breast cancer. The inverse correlation between ER and NF- $\kappa \mathrm{B}$ activity is further supported by the fact that some breast tumours, resistant to the tumoricidal effect of antiestrogens, become sensitised to apoptosis and show a reduction in NF- $\kappa$ B activity after treatment with oestrogen (Jordan, 2004). This suggests that the proapoptotic effects of oestrogen in these tumours are mediated through inhibition of NF- $\kappa B$ (Jordan, 2004). In our previous study, the significant increase in NF- $\kappa B$ target gene expression was not only linked to the IBC phenotype, but also to the ER status. In addition, a significantly elevated amount of transcriptionally active NF- $\kappa \mathrm{B}$ dimers in ER- tumours as compared to ER + tumours was observed (Van Laere et al, $2006 \mathrm{~b}$ ). The fact that IBC is more often ER- as compared to nonIBC is probably one of the reasons for increased NF- $\kappa B$ activation in IBC as compared to non-IBC.

Recent data suggest that all ER - breast tumours arise from ER + breast cancer cells that stop expressing ER. Proposed mechanisms for the origin of ER - breast cancers include that of pressures being exerted on ER + cells by oestrogen withdrawal, hypoxia, or overexpression of epidermal growth factor receptor or ErbB2 resulting in MAPK hyperactivation (Creighton et al, 2006). Hyperactive MAPK leads to the loss of ER expression. In addition, the indirect activation of NF- $\kappa \mathrm{B}$ due to MAPK hyperactivity plays a role in downregulating ER expression (Creighton et al, 2006). Recently, the importance of hyperactivated MAPK has been indicated by the fact that an EGFR/ErbB2-induced MAPK signature was able to correctly predict the ER status in four independent data sets with accuracies ranging from 68 to $87 \%$ (Creighton et al, 2006). This mechanism can also explain the apparent inverse correlation between ER and NF- $\kappa B$ activation.

In the present study, we investigated the activation of the NF- $\kappa B$ transcription factor in breast cancer in terms of ER signalling and the hyperactivation of MAPK due to EGFR and/or ErbB2 overexpression, with special emphasis on the IBC phenotype. We demonstrated that, NF- $\kappa B$ activation is not exclusively limited to IBC but more general to ER- breast tumours. In addition, we demonstrated that IBC is characterised by MAPK hyperactivation in comparison to non-IBC, potentially due to overexpression of EGFR and/or ErbB2. The activation of NF- $\kappa \mathrm{B}$ and the frequent ER independency of IBC tumours can be explained in this context. Altogether, these data indicate that NF- $\mathrm{BB}$ and MAPK might be therapeutic targets for IBC specifically and more general for ERbreast tumours as well as for breast tumours with acquired resistance against hormonal therapy.

\section{MATERIALS AND METHODS}

\section{Patients and samples}

Tumour samples were obtained from patients with breast adenocarcinoma treated in the General Hospital Sint-Augustinus, Wilrijk, Belgium. Each patient gave written informed consent. This study was approved by the local institutional review board. All samples were stored in liquid nitrogen within $15 \mathrm{~min}$ after excision (median delay of $9 \mathrm{~min}$ ). Breast tumour samples included 17 pretreatment samples of patients with IBC, diagnosed by strictly respecting the criteria mentioned in the TNM classification of the American Joint Committee on Cancer as T4d (Singletary et al, 2002). The presence of tumour emboli was, as an isolated pathological finding, not sufficient for the diagnosis of IBC. Of the 20 non-IBC samples, 10 represented LABC (7 T3, 3 T4), four samples represented T2-tumours and six represented T1-tumours. Thirteen patients with non-IBC had pathological axillary lymph node involvement. Baseline clinicopathologic characteristics for the IBC and non-IBC patients from which samples have been used for $\mathrm{qRT}$ - PCR analysis and IHC analysis are provided in Table 1 .

Table I Clinicopathological characteristics for the study population

\begin{tabular}{|c|c|c|c|c|}
\hline & \multicolumn{2}{|c|}{ PCR $(n=37)$} & \multicolumn{2}{|c|}{ cDNA array $(n=34)$} \\
\hline & $\begin{array}{c}\text { Non-IBC } \\
(n=20)\end{array}$ & $\begin{array}{c}\text { IBC } \\
(n=17)\end{array}$ & $\begin{array}{c}\text { Non-IBC } \\
(n=18)\end{array}$ & $\begin{array}{c}\text { IBC } \\
(n=16)\end{array}$ \\
\hline \multicolumn{5}{|l|}{ Age (years) } \\
\hline $\begin{array}{l}\text { Median } \\
\text { (range) }\end{array}$ & $61(42-78)$ & $56(4 \mid-74)$ & $61(42-78)$ & $56(4 \mid-74)$ \\
\hline \multicolumn{5}{|l|}{ Histological type } \\
\hline Ductal & 18 & 15 & 16 & 14 \\
\hline Lobular & 2 & 2 & 2 & 2 \\
\hline \multicolumn{5}{|c|}{ Tumour emboli in dermal lymph vessels } \\
\hline Present & 2 & 14 & 2 & 13 \\
\hline Absent & 18 & 3 & 16 & 3 \\
\hline \multicolumn{5}{|l|}{ Grade $^{\mathrm{a}}$} \\
\hline I & 6 & 0 & 5 & 0 \\
\hline 2 & 8 & 8 & 8 & 7 \\
\hline 3 & 6 & 9 & 5 & 9 \\
\hline \multicolumn{5}{|l|}{ T-Stadium } \\
\hline I & 6 & 0 & 5 & 0 \\
\hline 2 & 4 & 0 & 3 & 0 \\
\hline 3 & 7 & 0 & 7 & 0 \\
\hline 4 & 3 & 17 & 3 & 16 \\
\hline \multicolumn{5}{|l|}{ N-Stadium ${ }^{b}$} \\
\hline 0 & 8 & 0 & 7 & 0 \\
\hline I & 11 & 6 & 10 & 5 \\
\hline 2 & I & 11 & । & 11 \\
\hline \multicolumn{5}{|l|}{ ER-status ${ }^{c}$} \\
\hline ER negative & 5 & 13 & 4 & 12 \\
\hline ER positive & 15 & 4 & 14 & 4 \\
\hline \multicolumn{5}{|l|}{$P R$-status ${ }^{d}$} \\
\hline PR negative & 9 & 14 & 7 & 13 \\
\hline PR positive & 11 & 3 & 11 & 3 \\
\hline
\end{tabular}

$\mathrm{IBC}=$ inflammatory breast cancer. ${ }^{\mathrm{a}}$ According to the Elston-Ellis modification of the SBR grading system. 'The N-Stadium for patients with IBC was determined clinically. 'ER status determined using the anti-ER antibody (PharmDX) and a cutoff level of $10 \%$ to discriminate between absence or presence of nuclear protein expression. ${ }^{d} P R$ status determined using the anti-PR antibody (clone PoR I249) and a cutoff level of $10 \%$ to discriminate between absence or presence of nuclear protein expression. 


\section{RNA isolation, reverse transcription and quantitative real-time RT-PCR}

For quantitative Real-Time RT-PCR, RNA was isolated as described before from all samples (Van Laere et al, 2005, 2006b). One microgram of RNA from 17 IBC samples and 20 non-IBC samples in total was reverse transcribed into cDNA with random primers (High Capacity cDNA Archive Kit, Applied Biosystems, Foster City, CA, USA). PCR primers and Taqman probes for eight NF- $\kappa \mathrm{B}$ target genes (vascular cell adhesion molecule 1 (VCAM1), CC chemokine receptor 5 (CCR5), superoxide dismutase 2 (SOD2), interleukin 15 (IL15), cathepsin B (CTSB), interferon regulatory factor 7 (IRF7), guanylate-binding protein 1 (GBP1), CD48 antigen (CD48)), ER- $\alpha$, ER- $\beta$ and 11 putative ER target genes (PR (PGR), GATA-binding protein 3 (GATA3), mucin 1 (MUC1), x-box binding protein 1 (XBP1), oncogene MYB (MYB), B-cell translocation gene 2 (BTG2), transforming growth factor $\beta 3$ (TGFb3), Ras-associated protein RAB31 (RAB31), START domain containing 10 (STARD10), hydroxysteroid dehydrogenase $17 \quad \beta 4$ (HSD17b4) and TRIpartite motif-containing protein 25 (TRIM25)) and two housekeeping genes were purchased as assays-on-demand products for gene expression (Applied Biosystems). Putative ER target genes were selected based upon a constitutive overexpression in ER + breast tumours in three independent genome-wide breast cancer profiling studies (Abba et al, 2005). 18S ribosomal RNA and $\beta$-actin were used as housekeeping genes to control for reverse transcriptase efficiency, RNA degradation, PCR inhibition and RNA input. Human Universal Reference RNA (Stratagene, La Jolla, CA, USA) was used as calibrator to calculate relative gene expression for the above-mentioned genes. Quantitative real-time RT-PCR was performed on the ABI 7700 Sequence Detector (Applied Biosystems). All PCRs were performed in duplicate. Relative Gene Expression (RGE) was calculated with the 2-ddCt method (Livak and Schmittgen, 2001) as described before (Van Laere et al, 2005, 2006b).

\section{Immunohistochemistry}

For NF- $\kappa$ B, EGFR and ErbB2, antibodies purchased from Santa Cruz Biotechnology (Santa Cruz, CA, USA) were used for immunohistochemical (IHC) staining of RelA (clone C-20, sc-372), RelB (clone C-19, sc-226), NFkB1 (clone C-19, sc-1190), NFkB2 (clone K-27, sc-298), cRel (clone B-6, sc-6955), EGFR (clone 1005, sc-03) and ErbB2 (clone F-11, sc-7301). Formalin-fixed, paraffin-embedded tissue sections from 17 IBC tumours and 20 non-IBC tumours were rehydrated through sequential changes of alcohol and distilled water. Antigen retrieval was performed for $30 \mathrm{~min}$ in citrate buffer ( $\mathrm{pH}$ 6) for RelA, RelB, NFkB1, NFkB2 and EGFR at $95^{\circ} \mathrm{C}$. For cRel and ErbB2, antigen retrieval was performed for $30 \mathrm{~min}$ in Tris-EDTA buffer ( $\mathrm{pH}$ 9) at $95^{\circ} \mathrm{C}$. Sections were incubated for $1 \mathrm{~h}$ at room temperature using a dilution of respectively $0.2,4.0,1.3,2.7,2.0,8.0$ and $4.0 \mu \mathrm{g} \mathrm{ml}^{-1}$. The Dako Envision system on the Dako Cytomation autostainer was used for visualisation of the antibody binding. Tissue sections were counterstained using haematoxylin and mounted for light microscopy. For NF- $\kappa \mathrm{B}$, hot spots with nuclear staining were searched for in each tissue section and within these hot spots a total number of 500 nuclei was counted at a magnification of $\times 400$. Transcriptionally active NF- $\kappa \mathrm{B}$ dimers have been determined as described before (Van Laere et al, 2006b). The HER2/neu score using the HercepTest (DakoCytomation, Glostrup, Denmark) was interpreted on a $0-3$ score $(0=$ no staining or membranous staining in less than $10 \%$ of tumour cells; $1=$ faint or barely perceptible partial membranous staining in more than $10 \%$ of tumour cells; 2 = weak to complete membranous staining in more than $10 \%$ of tumour cells; $3=$ strong complete membranous staining in more than $10 \%$ of tumour cells). Based on this score, the HER2/neu status was determined: Score 0-1 was considered negative, Scores 2 and 3 was considered positive. For EGFR, the same scoring system was used (Van den Eynden et al, 2004). Immunohistochemical overexpression of ErbB2 $(2+$ or $3+)$ was confirmed by FISH.

For ER quantification, the ER PharmDX (Dako) assay was used. The ER/PR PharmDX assay is an FDA-approved assay, which consists of a cocktail of two mouse monoclonal antibodies to ER (clones 1D5 and ER-2-123), a negative reagent control containing appropriate Ig concentrations equivalent to the primary antibodies, and cell line control slides. Each cell line control slide contains sections of two pelleted formalin-fixed, paraffinembedded cell lines, which represent a moderate level of ER and PR protein expression (cell line CAMA-1) and a negative cell line (cell line HT-29). Formalin-fixed and paraffin-embedded tissue sections were rehydrated through sequential changes of alcohol and distilled water. Antigen retrieval was performed at $125^{\circ} \mathrm{C}$ during $5 \mathrm{~min}$ in a pressure cooker using Target Retrieval Solution (Dako) followed by cooling down the pressure cooker during 30 min without venting of pressure. Tissue sections were incubated during $30 \mathrm{~min}$ at room temperature. Again, the Dako Envision system on the Dako Cytomation autostainer was used for visualisation of the antibody binding and tissue sections were counterstained using haematoxylin and mounted for light microscopy. A tumour sample was regarded positive when at least $10 \%$ of all tumour cells on the slide showed nuclear staining.

\section{cDNA microarrays}

cDNA microarrays have been executed as described before (Van Laere et al, 2005) on the same patients except for one IBC and two non-IBC breast tumours. High-quality RNA was reverse transcribed, amplified and Cy5 labelled using the Amino Ally MessageAmp aRNA Kit (Ambion Inc., Austin, TX, USA). Universal Human Reference RNA (Stratagene) was processed similarly and $\mathrm{Cy} 3$ labelled for competitive hybridisation. cDNA chips were obtained from the Sanger Center and hybridised during $16 \mathrm{~h}$ at $47^{\circ} \mathrm{C}$ in a volume of $40 \mu \mathrm{l}$. Information regarding the clone set and the microarray production can be obtained from the World Wide Web: www.sanger.ac.uk/Projects/Microarrays. After hybridisation, slides were washed and scanned immediately using ScanArray software. Data were generated using Quantarray software and analysed using GeneSpring (Agilent Technologies, Palo Alto, CA, USA). The methodology has been described in Van Laere et al (2005). Baseline clinicopathologic characteristics for the IBC and non-IBC patients from which samples have been used for cDNA microarray analysis are provided in Table 1.

EGFR, ErbB2, MEK and RAF gene expression signatures, described by Creighton et al (2006), were mapped onto our tumour data set using the Locus Link ID resulting in the identification of $54,55,50$ and 56 common genes respectively. These genes were combined into a MAPK signature of 223 genes represented by 283 clones in our IBC/non-IBC data set (Gene list available as Supplementary information). This MAPK signature was then analysed using Pathway-Express (http://vortex.cs.wayne. edu/projects.htm) to investigate which pathways are over-represented in this gene list. The performance of this MAPK signature to discriminate between ER + and ER- samples was tested on the Sotiriou data set (Sotiriou et al, 2003). Therefore, we submitted the Sotiriou series of 99 breast tissue samples to hierarchical clustering based on the expression of the 223 gene set. Normalised and $\log 2$ transformed expression data for 223 genes were extracted, mediancentred on genes and analysed using unsupervised hierarchical clustering with Pearson correlation as similarity metric. Clustering was visualised using GeneSpring.

$\mathrm{Next}$, to investigate common biological themes in our own IBC/ non-IBC data set defined by the MAPK signature, unsupervised hierarchical clustering, using centroid linkage clustering with the 
Pearson correlation coefficient as similarity metric was applied. Global views of the variation in gene expression among the different breast cancer samples defined by the MAPK signature were obtained using principal component analysis on our IBC/ non-IBC data set, with the MAPK signature as input data set.

\section{Statistical analysis}

All statistical analysis, except for microarray analyses, have been performed in SPSS (SPSS Inc., Version 12.0, Chicago, IL, USA). Gene expression differences or differences in the percentage of immunostained tumour cell nuclei between two conditions of interest were analysed using the Mann-Whitney $U$-test. Correlations between two binary variables were examined using a Pearson $\chi^{2}$ test. Correlations between gene expression data were calculated using the Spearman correlation coefficient. Differences or correlations were considered significant when the $P$-value was below 0.05 . To investigate common biological themes defined by the expression of ER- $\alpha$, ER- $\beta$, ER target genes and $\mathrm{NF}-\kappa \mathrm{B}$ target genes, unsupervised hierarchical clustering has been executed using gene expression data for all NF- $\kappa \mathrm{B}$ and ER target genes. Correlations between the clustering patterns and the ER status or the breast tumour phenotype were investigated using a Pearson $\chi^{2}$ test.

\section{RESULTS}

\section{Increased activation of NF- $\mathrm{KB}$ in $\mathrm{ER}-$ breast tumours compared to $\mathrm{ER}+$ breast tumours}

We compared the expression of eight NF- $\mathrm{B}$ target genes in ER + and ER - breast tumours. Median gene expression levels for all NF$\kappa \mathrm{B}$ target genes were elevated in ER- breast tumours compared to $\mathrm{ER}+$ breast tumours. For 6 out of $8 \mathrm{NF}-\kappa \mathrm{B}$ target genes the differences in gene expression between ER + and ER- breast tumours reached significance. Gene expression data for all NF- $\kappa \mathrm{B}$ target genes in ER - and ER + breast tumours are presented as a scatter plot in Figure 1A. Median gene expression values for the NF- $\kappa \mathrm{B}$ target genes in ER - and ER + breast tumours are indicated by a horizontal bar.

We observed a significant difference between the percentage immunostained nuclei for NFKB1 between ER $+(42.20 \%)$ and ER- $(61.20 \%)$ breast tumours $(P=0.002)$ For RelB, a trend towards a significant difference in the percentage of immunostained nuclei was observed (RelB immunostained nuclei in ER + breast tumours: $29.60 \%$, RelB immunostained nuclei in ER- breast tumours: $52.30 \% ; P=0.092)$. For RelA, cRel and NFkB2, no significant difference was found for the percentage of immunostained nuclei between ER - and ER + breast tumours. Next, we looked for transcriptionally active NF- $\mathrm{KB}$ dimers in ER - and ER + breast tumours. Therefore, we dichotomised the percentage of immunostained nuclei for each NF- $\kappa \mathrm{B}$ transcription factor relative to a cutoff level of $50 \%$. Then, for each sample in our study, we identified transcriptionally active NF- $\kappa \mathrm{B}$ dimers by means of examining coexpression of the members of the NF- $\kappa B$ transcription factor family. The detailed methodology was previously described and validated (Van Laere et al, 2006b). Hence, we identified 12 out of $18 \mathrm{ER}$ - breast tumours with transcriptionally active NF- $\kappa \mathrm{B}$ compared to only 1 out of $19 \mathrm{ER}+$ breast tumours with transcriptionally active NF- $\kappa \mathrm{B}(\kappa=-0.609, P<0.0001)$.

\section{Activation of ER and NF- $\mathrm{KB}$ transcription factors is inversely correlated}

To further investigate the inverse relationship between NF- $\kappa B$ signalling and ER signalling, the expression of ER- $\alpha$, ER- $\beta$ and 11 putative ER target genes was compared between tumours with and without transcriptionally active NF- $\mathrm{KB}$ dimers present. Out of
11 ER target genes, four ER target genes showed significant differences between tumours with and without transcriptionally active NF- $\kappa \mathrm{B}$ : GATA3 $(P=0.001)$, MYB $(P=0.004), \mathrm{HSD} 17 \beta 4$ $(P=0.030)$ and STARD10 $(P=0.013)$. For XBP1 $(P=0.083)$, BTG2 $(P=0.072)$ and RAB31 $(P=0.053)$ a trend towards significant overexpression was observed. For MUC1 $(P=0.200)$, TGF $\beta 3$ $(P=0.236)$, TRIM25 $\quad(P=0.937) \quad$ and $\quad$ PGR $\quad(P=0.132)$ no significant differences were observed. The median gene expression levels were elevated in IHC NF- $\kappa \mathrm{B}$ - tumours compared to IHC NF- $\kappa \mathrm{B}+$ tumours for all ER target genes, except TRIM25. In addition, median gene expression levels for ER- $\alpha$ were significantly elevated in IHC NF- $\kappa \mathrm{B}$ - breast tumours compared to IHC NF- $\kappa \mathrm{B}+$ breast tumours $(P=0.003)$. However, gene expression data for ER- $\beta$ was significantly upregulated in IHC $\mathrm{NF}-\kappa \mathrm{B}+$ breast tumours compared to IHC NF- $\kappa \mathrm{B}-$ breast tumours $(P=0.023)$. Gene expression data for different ER target genes in NF- $\kappa \mathrm{B}+$ and NF- $\kappa \mathrm{B}-$ breast tumours are displayed in Figure 1B. Median gene expression values for the different ER target genes in NF- $\mathrm{KB}+$ and $\mathrm{NF}-\mathrm{\kappa B}-$ breast tumours are indicated by a horizontal bar.

$\mathrm{NF}-\kappa \mathrm{B}$ target gene expression data were correlated with gene expression data for ER- $\alpha$, ER- $\beta$ and 11 ER target genes using Spearman correlation coefficients. Data are represented in a heatmap format (Figure 2), in which correlation coefficients are colour coded, with red indicating a positive correlation coefficient and green indicating a negative correlation coefficient. Colour saturation indicates the strength of the correlation coefficient. All $\mathrm{NF}-\kappa \mathrm{B}$ target genes and most ER target genes are strongly correlated with each other, indicated by the red squares in the heatmap at the point of intersection between the ER target genes on the one hand and NF- $\kappa B$ target genes on the other. Out of 28 comparisons between NF- $\kappa \mathrm{B}$ target genes and 78 comparisons between ER- $\alpha$, ER- $\beta$ and 11 ER target genes, respectively 28 and 67 comparisons were positively correlated and in respectively 96 and $62 \%$ of the cases, the positive correlation coefficient reached significance (positive Spearman correlation coefficients ranging from 0.285 to 0.879 ). Interestingly, ER- $\beta$ was anticorrelated with ER- $\alpha$ and 7 out of 11 ER target genes, with anticorrelation coefficients reaching significance in four comparisons. Most of the NF- $\kappa \mathrm{B}$ and ER target genes are anticorrelated, indicated by the green squares in the heatmap at the point of intersection between the ER and NF- $\kappa \mathrm{B}$ target genes. In total, 104 comparisons have been made between ER and NF- $\mathrm{BB}$ target genes, from which 77 were anticorrelated and in $40 \%$ of the cases the anticorrelation was significant (negative Spearman correlation coefficients ranging from -0.283 to -0.584 ). These data indicate an inverse correlation between the activation of the NF- $\kappa B$ on the one hand and ER on the other. Gene expression data for ER- $\beta$ were positively correlated with gene expression data for all NF- $\mathrm{KB}$ target genes, and correlation coefficients reached significance in five comparisons.

We then applied unsupervised hierarchical clustering to the ER and NF- $\kappa \mathrm{B}$ target gene expression data to investigate common biological themes defined by the combined ER and NF- $\kappa B$ signature. The clustering output is displayed in Figure 3. Two major sample clusters have been identified, as well as two major gene clusters. The gene clusters represented the NF- $\kappa \mathrm{B}$ target gene signature on the one hand and the ER target gene signature on the other hand. A first sample cluster was characterised by an increased expression of the NF- $\kappa B$ signature and a decreased expression of the ER signature. A second sample cluster was characterised by an increased expression of the ER target gene signature and a decreased expression of the NF- $\kappa \mathrm{B}$ target gene signature. The first sample cluster was characterised by an increased amount of IBC samples. Out of 17 IBC samples, 12 IBC samples belonged to the NF- $\kappa \mathrm{B}$ positive cluster whereas five IBC samples belonged to the $N F-\kappa B$ negative cluster. Out of 20 non-IBC samples, 13 non-IBC samples belonged to the 
Relative gene expression $\log \left(2^{\wedge}-d d C t\right)$

\begin{tabular}{l} 
ERa NFkB- \\
\cline { 3 - 5 }
\end{tabular}

Relative gene expression $\log \left(2^{\wedge}-d d C t\right)$
]$P=0.003$
]$P=0.132$

]$P=0.023$

$P=0.001$

]$P=0.200$

]$P=0.083$

]$P=0.004$

$P=0.072$

]$P=0.236$

]$P=0.053$

$P=0.013$

\rceil $P=0.030$

]$P=0.937$

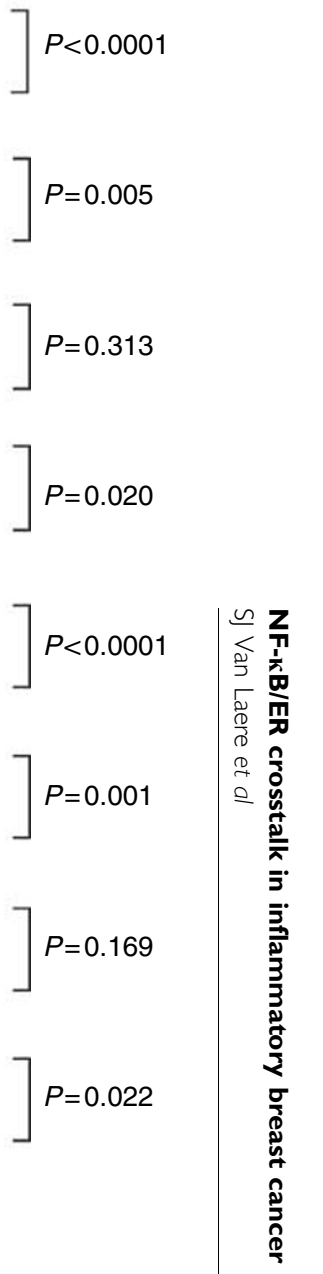

Molecular Diagnostics 


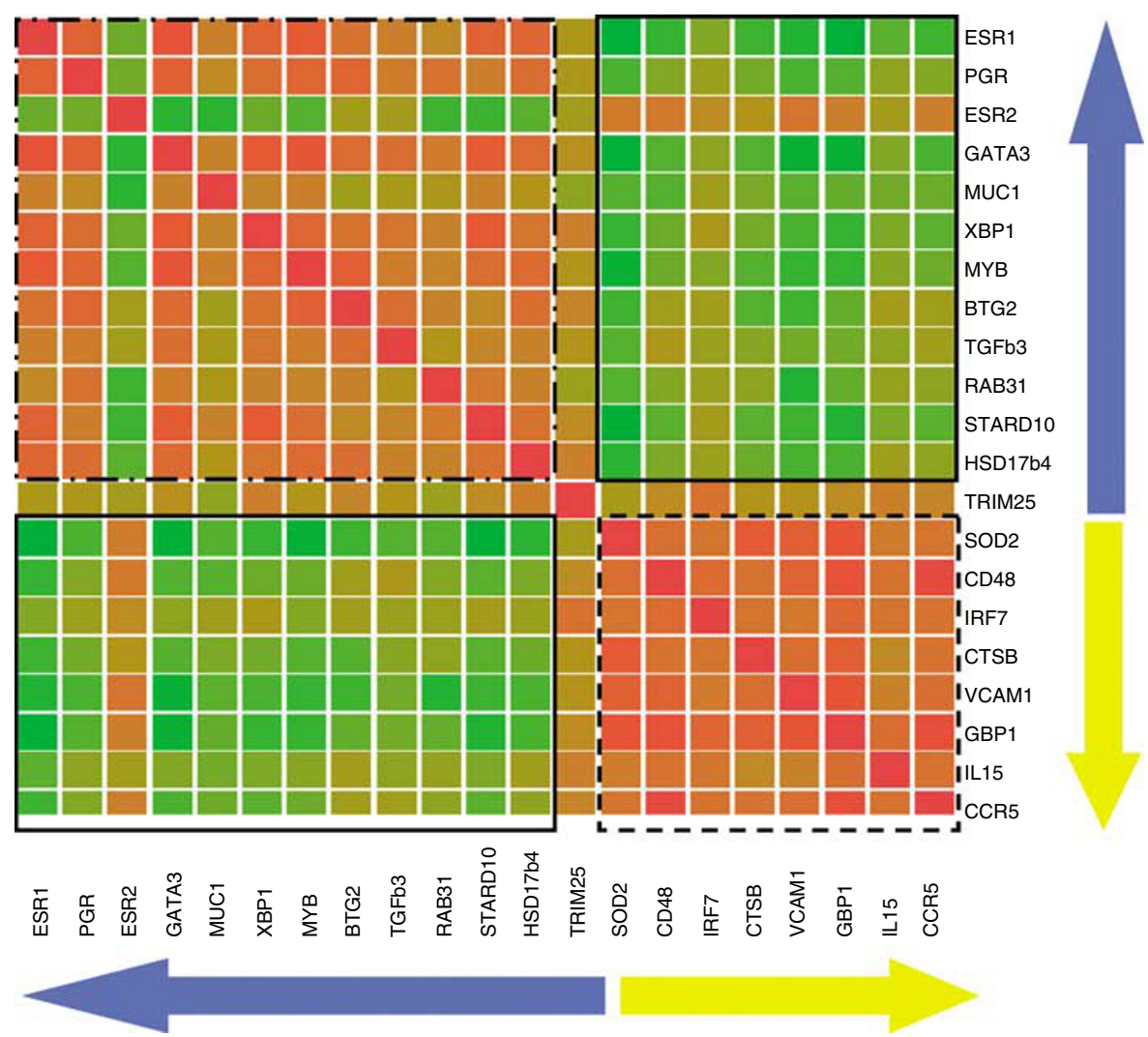

Figure 2 Heatmap comparing gene expression profiles of each gene in the ER/NF-KB signature with each other. Correlation coefficients are colour coded, with red indicating positive correlation coefficients and green indicating negative correlation coefficients. Colour saturation indicates the strength of the correlation coefficients. The blue arrow indicates the ER target genes, the yellow arrow indicates the NF- $\mathrm{BB}$ target genes. Two red squares are clearly visible at the points of intersection between the ER target genes on the one hand and the NF- $\mathrm{BB}$ target genes on the other, indicating positive correlations (dashed squares). Green squares are visible at the points of intersection between ER and NF-KB target genes, indicating inverse correlations (straight squares).

NF- $\kappa \mathrm{B}$ negative cluster and seven non-IBC samples belonged to the NF- $\kappa B$ positive cluster (Pearson $\chi^{2} ; P=0.001$ ). However, when looking at the ER status, out of 19 samples in cluster 1,15 samples were identified as being ER-. Out of 18 samples in cluster 2, again 15 samples were identified as being ER + (Pearson $\left.\chi^{2} ; \quad P<0.0001\right)$, indicating that elevated NF- $\mathrm{BB}$ activation is more common in ER- breast tumours, independent of the IBC of non-IBC phenotype and that the frequent activation of NF- $\kappa B$ in IBC is caused by the frequent ER negativity of IBC specimens.

\section{EGFR/ErbB2-MAPK hyperactivation leads to NF-кB activation and ER downregulation}

The MAPK signature composed of 223 genes up- or downregulated in MCF7 cell lines, after transfection with EGFR (+ EGF), ErbB2, RAF and MEK was first analysed using Pathway-Express to investigate which signal transduction pathways are represented in this gene list. Not surprisingly, the MAPK pathway was most significantly linked to the MAPK signature (Rank 1, $P<0.001)$. However, other important signal transduction pathways were also represented in the MAPK signature among which: Wnt signalling pathway (Rank 5, $P=0.005$ ), Notch signalling pathway (Rank 6, $P=0.006$ ), VEGF signalling pathway (Rank 7, $P=0.008$ ) and the Toll-like receptor signalling pathway (Rank 10, $P=0.009$ ).

Next, we tested the MAPK signature for performance by unsupervised hierarchical clustering on the Sotiriou data (Sotiriou et al, 2003) set to identify ER status. The output of the clustering analysis is shown in Figure 4A. We identified one large cluster that was mainly composed of ER + specimens (58 out of 63 ) and two smaller clusters mainly composed of ER - specimens (29 out of 36) (Pearson $\left.\chi^{2}, P<0.0001\right)$. In total, the performance of the MAPK signature in predicting the ER status by unsupervised analysis of the Sotiriou data set (Sotiriou et al, 2003) was $88 \%$. This clearly demonstrated that the MAPK signature is capable of predicting ER status.

Next, the MAPK signature was applied onto our own IBC/nonIBC data set (Van Laere et al, 2005) by unsupervised hierarchical clustering analysis. The output of the clustering analysis is shown in Figure 4B. We identified two clusters, one which was mainly enriched in ER- breast cancer specimens ( 9 out of 12) and a second which was mainly enriched in ER + breast cancer specimens (15 out of 22) (Pearson $\chi^{2}, P<0.001$ ), resulting in an accurate prediction of IHC ER status in $71 \%$ of the cases. However, when looking at the distribution of the different IBC/non-IBC samples over the different clusters, we found that the first cluster was exclusively composed of IBC specimens (12 out of 12), whereas the second cluster was mainly composed of non-IBC specimens (18 out of 22) (Pearson $\chi^{2}$, $P<0.0001)$, resulting in an accurate prediction of the tumour phenotype in $88 \%$ of the cases. We then performed a principle component analysis with the MAPK signature as input data set to obtain global views of the variation in the IBC/non-IBC data set, defined by the MAPK signature. We identified that the expression of the first metagene, being the first principal component generated by the principal component analysis, accounting for approximately $44 \%$ of the total variation seen in this data set, was significantly overexpressed in IBC (median: 1.127) compared to non-IBC 


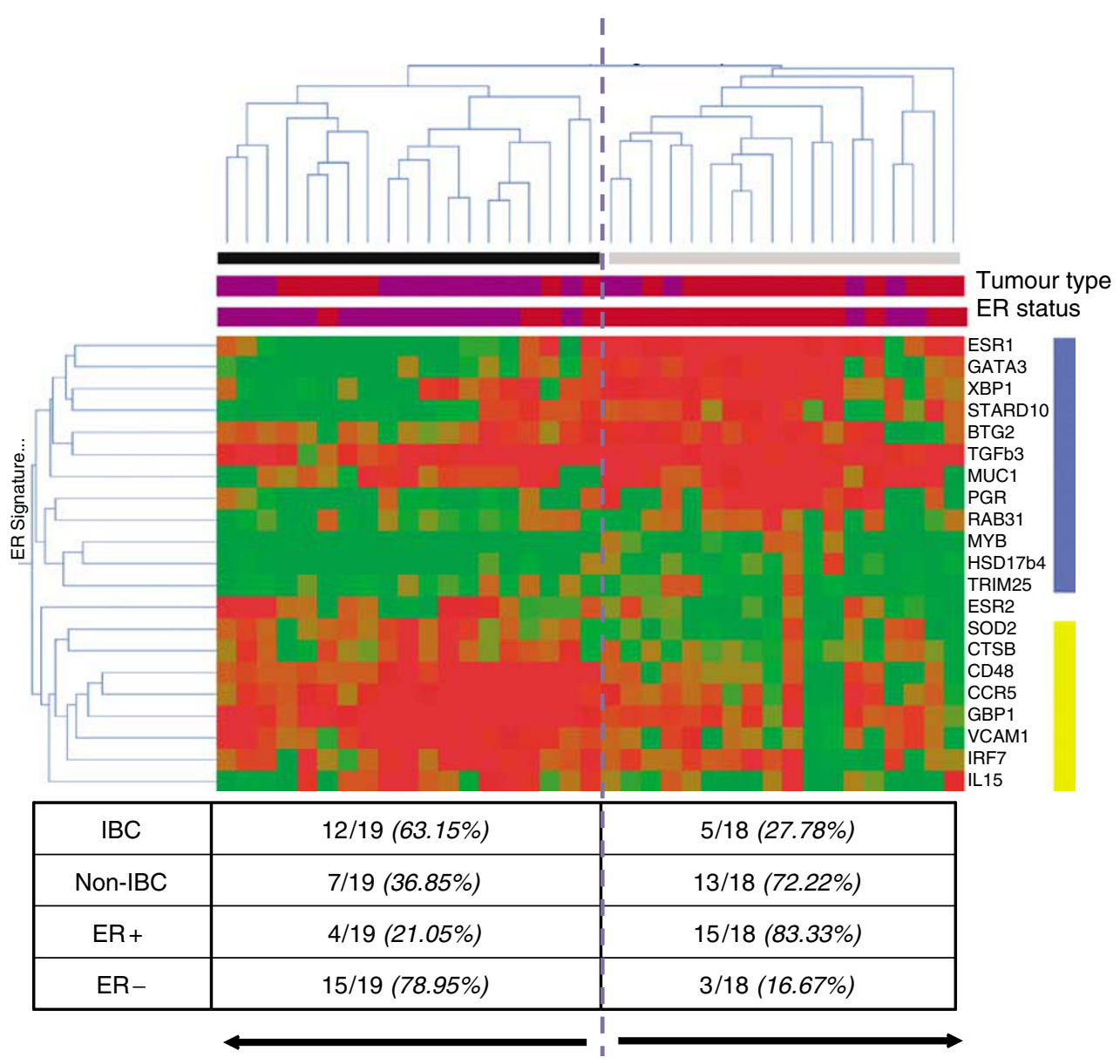

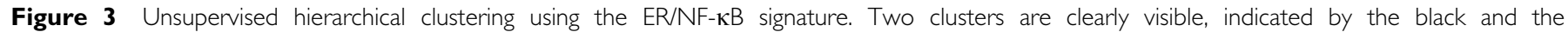
grey bar underneath the dendrogram. Gene expression data are represented in matrix format, with rows indicating genes and columns indicating samples. Overexpressed genes are colour coded red and repressed genes are colour coded green. Colour saturation indicates the level of overexpression or repression. The NF-אB signature is indicated by a yellow bar and the ER signature is indicated by a blue bar (right of the matrix). Tumour type (IBC or non-IBC) and ER status (ER + or ER-) is represented underneath the dendrogram using purple (IBC and ER- respectively) and brown (non-IBC and ER + respectively) bars. The cluster indicated by the black bar contains 12 out of 19 IBC samples and I5 out of 19 ER- breast tumour samples. The cluster indicated by the grey bar contains 13 out of 18 non-IBC samples and 15 out of 18 ER + breast tumour samples.

(median: 0.904) $(P<0.001)$. The expression profile of the first metagene is drawn underneath the clustering output in Figure $4 \mathrm{~B}$. The red line indicated a relative gene expression level of 1 . Most IBC specimens have a strongly elevated expression for the first metagene (above 1) whereas most non-IBC specimens have a reduced expression for the first metagene (beneath 1).

Next, we analysed if the samples with a strong expression for the first metagene were also characterised by an overexpression of EGFR and/or ErbB2. Therefore, we performed IHC for EGFR and ErbB2 (Figure 4C) and scored membranous staining. IHC data were then mapped onto the dendrogram and the results are shown in Figure 4B. Most samples characterised by an elevated expression for the first metagene were also characterised by an overexpression of EGFR and/or ErbB2 as shown in Figure 4B. The expression of the first metagene was significantly elevated in tumours characterised by EGFR/ErbB2 overexpression (median: 1.109) compared to tumours without overexpression of EGFR or ErbB2 (median: 0.909) $(P=0.004)$.

Finally, IHC data for EGFR and/or ErbB2 overexpression were correlated with tumour phenotype (IBC/non-IBC), ER status and the presence of transcriptionally active NF- $\kappa B$ dimers. The presence of membranous staining for EGFR and/or ErbB2 was significantly correlated with tumour phenotype. We identified 13 out of 17 IBC tumours with EGFR and/or ErbB2 overexpression compared to only one non-IBC tumour with EGFR and/or ErbB2 overexpression $(\kappa=0.742, P<0.0001)$. Out of 13 samples with transcriptionally active NF- $\kappa \mathrm{B}$ dimers, nine showed overexpression of EGFR and/or ErbB2 whereas out of 24 tumours without transcriptionally active NF- $\kappa B$ dimers only five showed overexpression of EGFR and/or ErbB2 $(\kappa=0.476$, $P=0.004)$. The overexpression of EGFR and/or ErbB2 was also significantly anticorrelated with ER status. Out of 19 ER + breast tumours 15 showed no overexpression of EGFR and/or ErbB2 whereas 10 out of $18 \mathrm{ER}-$ breast tumours showed overexpression of EGFR and/or ErbB2 $(\kappa=-0.343, P=0.031)$. Using tumour phenotype (IBC or non-IBC), ER expression and presence of transcriptionally active $\mathrm{NF}-\kappa \mathrm{B}$ as independent variables and EGFR and/or ErbB2 overexpression as dependent variable, a logistic regression was performed. Tumour phenotype was identified as the most predictive parameter to discriminate between tumour samples with EGFR and/or ErbB2 overexpression and without EGFR and ErbB2 overexpression $(\beta=18.039$; $P=0.038)$. The presence of transcriptionally active NF- $\kappa \mathrm{B}$ $(\beta=7.720 ; \quad P=0.092)$ and expression of $\operatorname{ER}(\beta=-6.800$; $P=0.122$ ) were both not significantly associated with EGFR and/ or ErbB2 overexpression in this model. 

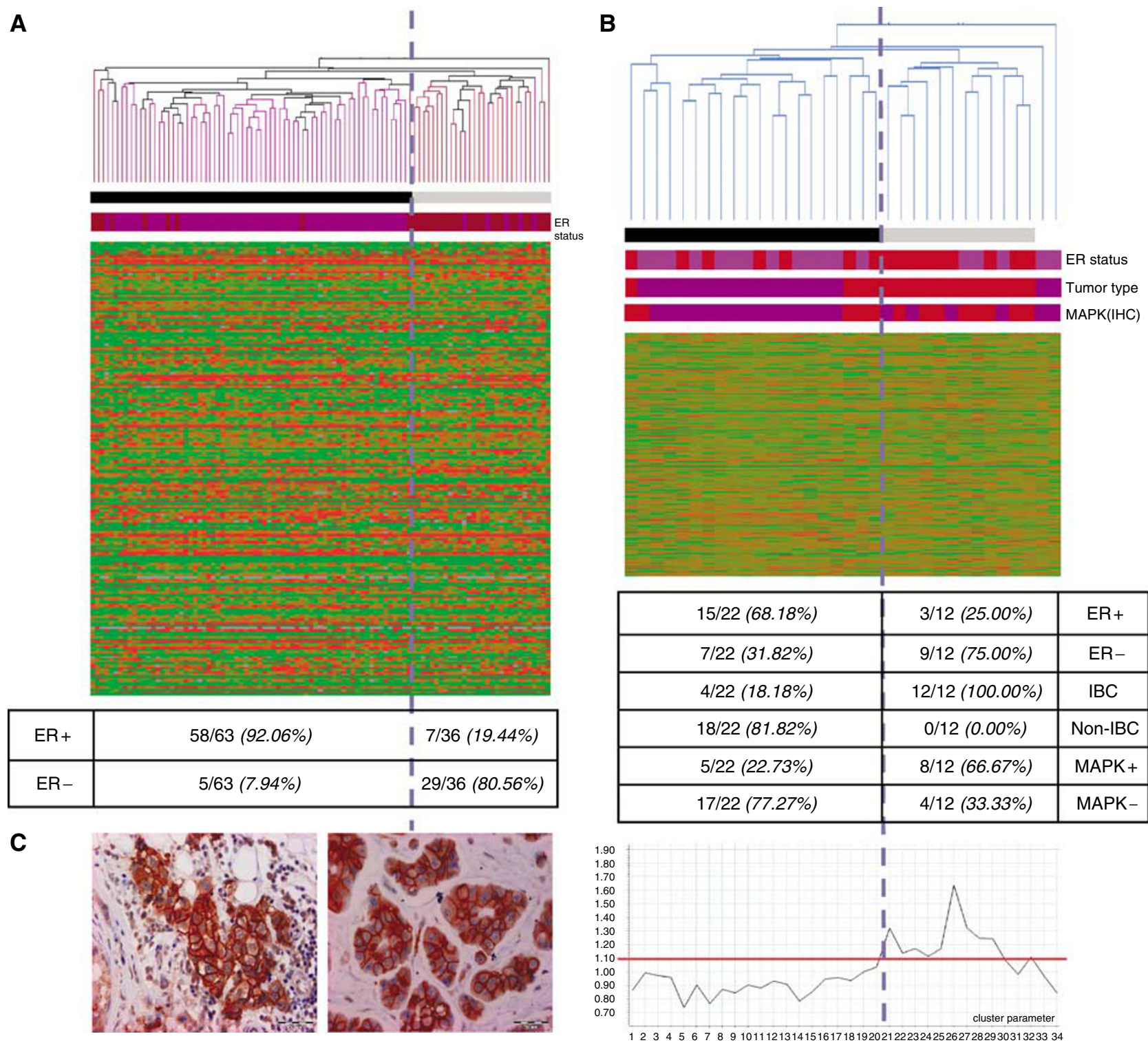

Figure 4 The performance of the MAPK signature for prediction of ER status was validated using the Sotiriou data set (A). Unsupervised hierarchical clustering was executed. Data are represented in matrix format, with rows indicating genes and columns indicating samples. Overexpressed genes are colour coded red and repressed genes are colour coded green, missing values are colour coded grey. Colour saturation indicates the level of overexpression or repression. Two clusters have been identified indicated by the black and grey bars underneath the dendrogram. ER status is represented by the purple $(E R+)$ and brown $(E R-)$ bar. The MAPK signature was then applied onto our own IBC/non-IBC expression data set using unsupervised hierarchical clustering (B). Again, data are represented in a matrix format, with rows representing genes and columns representing samples. Overexpressed genes are colour coded red and repressed genes are colour coded green. The level of overexpression or repression is represented by the colour saturation. Two clusters have been identified indicated by the black and grey bars underneath the dendrogram. Tumour type (IBC or non-IBC), ER status (ER + or ER-) and MAPK status (presence or absence of EGFR and/or ErbB2 overexpression) are indicated using brown (IBC, ER- and presence of EGFR and/or ErbB2 overexpression respectively) and purple (non-IBC, ER+ and absence of EGFR and/or ErbB2 overexpression respectively) bars. The cluster indicated by the black bar contains I5 out of 22 ER + breast tumour samples, 18 out of 22 non-IBC specimens and 17 out of 22 MAPK-negative breast tumour specimens. The cluster indicated by the grey bar contains 9 out of 12 ER- breast tumour samples, 12 out of 12 IBC specimens and 8 out of 12 MAPK + breast tumour specimens. The expression profile of the first metagene, representing approximately $44 \%$ of the total variation seen within this data set, is shown underneath the matrix. The red line indicates a relative gene expression level of I (reference). Microphotographs showing membranous staining for EGFR (left) and ErbB2 (right) are displayed in $(\mathbf{C})$

\section{DISCUSSION}

The activation of NF- $\mathrm{B}$ has been described previously in human breast cancer and breast cancer cell lines and has been specifically linked to ER independency. Biswas et al reported that NF- $\kappa \mathrm{B}$ is activated more often in ER - human breast tumours compared with ER + breast tumours and most predominantly in ER- and
ErbB2 + breast tumours (Biswas et al, 2004). Zhou et al studied the activation of NF- $\kappa \mathrm{B}$ in two groups of ER + breast tumours. Early-stage primary breast cancer selected for lower ER content showed two- to fourfold increased NFkB1 and RelA DNA binding over a second set of primary breast cancer with higher ER content. This demonstrates that the level of NF- $\kappa \mathrm{B}$ activation is inversely correlated with ER content (Zhou et al, 2005). In a recent study, we 
described that the expression of several NF- $\kappa \mathrm{B}$ target genes was significantly elevated in IBC compared to non-IBC (Van Laere et al, 2006b). In addition, the increased activation status of NF- $\kappa B$ in IBC was confirmed by immunohistochemistry and DNA-binding experiments. Considering the fact that the activation of NF- $\kappa \mathrm{B}$ is generally linked to ER independency, these findings can be explained by the fact that, compared to non-IBC, IBC has a low frequency of ER + tumour specimens. In this study, we show that the activation of NF- $\kappa \mathrm{B}$ is indeed more generally linked to breast tumours without ER protein expression than specifically to the IBC phenotype. Breast tumours with transcriptionally active NF- $\mathrm{B}$ show reduced expression of most ER target genes, whereas ER + breast tumours show reduced expression of most NF- $\kappa \mathrm{B}$ target genes. The expression of ER- $\alpha$ and most ER target genes is anticorrelated with the expression of most NF- $\kappa B$ target genes in our data set of 37 IBC and non-IBC breast tumours, indicating an inverse correlation between ER and NF- $\kappa B$ activation. By means of unsupervised hierarchical clustering using the combined ER and NF- $\mathrm{KB}$ data set we identified two sample clusters, one of which was characterised by a low expression of ER target genes and high expression of NF- $\mathrm{KB}$ target genes, and a second with high expression of ER target genes and low expression of NF- $\kappa \mathrm{B}$ target genes. The distribution of the different tumour samples over both clusters showed that the activation of NF- $\kappa B$ was not exclusively linked to the IBC phenotype, but more generally to breast tumours without ER expression at protein level.

Several mechanisms resulting in the inverse correlation between NF- $\kappa B$ activation and ER activation have been proposed (Kalaitzidis and Gilmore, 2005). ER has been shown to block NF- $\kappa B$ activity at several steps: (a) it can inhibit the IKK activity; (b) it can inhibit degradation of $\mathrm{I} \kappa \mathrm{B}$; (c) it can block DNA binding by NF- $\kappa \mathrm{B}$; (d) it can bind coactivators and compete with NF- $\mathrm{KB}$ for coactivators binding; and (e) it can directly bind to DNA-bound NF- $\kappa$ B to inhibit NF- $\kappa \mathrm{B}$-mediated transcriptional activation. In addition, the cross-coupling between ER and NF- $\mathrm{KB}$ also results in reduced activity of promoters with ER binding sites (Stein and Yang, 1995). The inverse correlation between NF- $\kappa \mathrm{B}$ activation and ER activation can also be explained alternatively. Recent evidence suggests that all ER- breast tumours arise from ER + breast tumour cells that stop expressing ER- $\alpha$ (Creighton et al, 2006). One of the reasons for the downregulation of ER- $\alpha$ is the overexpression of EGFR and/or ErbB2 resulting in the hyperactivation of MAPK (Oh et al, 2001). This mechanism possibly involves the activation of NF-KB (Holloway et al, 2004). The importance of hyperactivated MAPK for the generation of ER - breast tumours has been demonstrated by the fact that a MAPK signature is able to discriminate between ER + and ER- breast tumours in four independent data sets with accuracies ranging from 68 to $87 \%$ (Creighton et al, 2006). The application of a MAPK signature to our own IBC/non-IBC data set resulted in the correct prediction of ER status in $70 \%$ of the cases. However, the separation between IBC and non-IBC samples, based on the MAPK signature, was even more strict, with almost all IBC specimens falling together in one cluster and almost all non-IBC specimens falling together in a second cluster, independent of ER status. The presence of the VEGF, Wnt, Notch and Toll-like Receptor signalling pathways in the MAPK signature may account for the clustering pattern. Previously, it has been extensively demonstrated that IBC is characterised by increased angiogenesis (Van der Auwera et al, 2004) for which VEGF signalling is very important. Additionally, microarray experiments have shown that Wnt and Notch signalling pathways are represented in an IBC gene expression signature (Van Laere et al, 2005). In addition, the Toll-like Receptor signalling pathway, also linked to the IBC gene expression signature (Van Laere et al, 2005), leads to the activation of NF- $\kappa B$, a hallmark of IBC (Van Laere et al, 2006b). Altogether, this clustering pattern again underscores the distinct biological phenotype of IBC. Additionally, these results agree with our findings that IBC more often displays features of the Basal-like or ErbB2-overexpressing cell-of-origin breast cancer subtypes (Van Laere et al, 2006a) as described by Perou et al (2000). Breast tumours belonging to these subclasses more often demonstrate respectively EGFR and ErbB2 overexpression (Nielsen et al, 2004).

From the expression of the first metagene in IBC and non-IBC we learned that IBC is characterised by a more frequent MAPK hyperactivation, which is reflected by the frequent overexpression of EGFR and/or ErbB2 in IBC compared to non-IBC. Previous studies have shown, that the MAPK pathway is involved in RhoC GTPase induced motility, invasion and angiogenesis in IBC (Van Golen et al, 2002). Other studies have shown that the stimulatory effect of the RhoC GTPaseactivity on tumour growth depends on NF- $\kappa \mathrm{B}$ activity (Benitah et al, 2003). One of the first molecular alterations characterised in IBC was the overexpression of RhoC (Van Golen et al, 1999). In combination with our data, this suggests that IBC is generally characterised by overexpression of EGFR and/or ErbB2, leading to MAPK-induced activation of NF- $\kappa B$, which then in turn results in RhoC overexpression and loss of ER expression. However, these associations have only been marginally underscored using a multivariate regression model, except for the association between tumour phenotype and EGFR and/or ErbB2 overexpression. This indicates that more elaborate research using a larger amount of breast tumours is needed to confirm the observed associations. In addition, it should be noted that our findings have been based upon correlations between gene expression and protein expression data. Further investigation, using IBC and non-IBC cell lines, should be performed to mechanistically confirm the proposed interactions. Nevertheless, our data are in close agreement on previously published research on NF- $\kappa B$ activation in breast cancer, both in cell lines and in human samples (Biswas et al, 2000; Zhou et al, 2005).

The absence of NF- $\kappa \mathrm{B}$ activation in ER + cancers remains remarkable, and is explained by specific inhibitory crosstalk between NF- $\kappa B$ and ER signalling. The precise intersection of ER with the NF- $\kappa B$ pathway is not clear, and may be at multiple points (as discussed above). The specific inactivation of NF- $\mathrm{B}$ signalling by ER and oestrogen implies a specific mechanism that is selected by ER + breast cancers. During endocrine therapy, resistance invariably develops. For agonist-antagonist drugs, such as Tamoxifen, a shift from antagonist to agonist activity appears to be an important mechanism of resistance. For newer aromatase inhibitors, which deprive tumours of oestrogen, resistance mechanisms are not yet described. NF- $\mathrm{B}$ activation, through escape from tonic inhibition by oestrogen, is a reasonable candidate mechanism for resistance to oestrogen deprivation. Hence, as suggested by our data, NF- $\mathrm{B}$ can be an important therapeutic target for patients treated with aromatase inhibitors developing resistance to oestrogen deprivation as well as for patients having EGFR and/or ErbB2 overexpression.

In conclusion, the MAPK signature performs better in separating IBC from non-IBC tumours than in distinguishing ER- from ER + breast tumours. This despite the clearly demonstrated performance of the MAPK signature in distinguishing ER- from $\mathrm{ER}+$ breast tumours in the Sotiriou data set. The elevated expression of the MAPK signature, characterizing IBC, is reflected by the high percentage of EGFR and/or ErbB2 overexpressing IBC tumours, which potentially leads to the frequent ER independency of IBC, as well as to an increased activation of $\mathrm{NF}-\kappa \mathrm{B}$, accounting for the inverse interaction between NF- $\kappa \mathrm{B}$ and ER activation. It should be noted that, the increased activation of NF- $\kappa B$ is not exclusively linked to the IBC phenotype, but more generally to ER-independent breast tumours, which 
have a more frequent EGFR and/or ErbB2 amplification, hence breast tumours belong to the Basal-like and ErbB2-overexpressing cell-of-origin subtypes respectively. The relationship between EGFR and/or ErbB2 overexpression, MAPK hyperactivation, NF$\kappa \mathrm{B}$ transcriptional activity and loss of ER protein expression in Basal-like or ErbB2-overexpressing breast tumours is currently under investigation.

\section{ACKNOWLEDGEMENTS}

This work was supported by the Fund for Scientific Research Flanders, Grant no G.0100.04N.

Supplementary Information accompanies the paper on British Journal of Cancer website (http://www.nature.com/bjc)

\section{REFERENCES}

Abba MC, Hu Y, Sun H, Drake JA, Gaddis S, Baggerly K, Sahin A, Aldaz CM (2005) Gene expression signature of estrogen receptor á status in breast cancer. BMC Genomics 6: 37

Benitah SA, Valeron PF, Lacal JC (2003) ROCK and nuclear factor-kappaBdependent activation of cyclooxygenase- 2 by Rho GTPases: effects on tumor growth and therapeutic consequences. Mol Biol Cell 14: 3041 - 3054

Biswas DK, Cruz AP, Gansberger E, Pardee AB (2000) Epidermal growth factor-induced nuclear factor kappa B activation: a major pathway of cell-cycle progression in estrogen-receptor negative breast cancer cells. Proc Natl Acad Sci USA 97: 8542 -8547

Biswas DK, Dai SC, Cruz A, Weiser B, Graner E, Pardee AB (2001) The nuclear factor kappa B (NF-kappa B): a potential therapeutic target for estrogen receptor negative breast cancers. Proc Natl Acad Sci USA 98: $10386-10391$

Biswas DK, Shi Q, Baily S, Strickland I, Ghosh S, Pardee AB, Iglehart JD (2004) NF-kappa B activation in human breast cancer specimens and its role in cell proliferation and apoptosis. Proc Natl Acad Sci USA 101: $10137-10142$

Colpaert CG, Vermeulen PB, Benoy I, Soubry A, van Roy F, van Beest P, Goovaerts G, Dirix LY, van Dam P, Fox SB, Harris AL, van Marck EA (2003) Inflammatory breast cancer shows angiogenesis with high endothelial proliferation rate and strong E-cadherin expression. $\mathrm{Br} \mathrm{J}$ Cancer 88: $718-725$

Creighton CJ, Hilger AM, Murthy S, Rae JM, Chinnaiyan AM, El-Ashry D (2006) Activation of mitogen-activated protein kinase in estrogen receptor alpha-positive breast cancer cells in vitro induces an in vivo molecular phenotype of estrogen receptor alpha-negative human breast tumors. Cancer Res 66: 3903-3911

Draper L (2006) Breast cancer: trends, risks, treatments, and effects. AAOHN J 54: $452-453$

Dumitrescu RG, Cotarla I (2005) Understanding breast cancer risk - where do we stand in 2005? J Cell Mol Med 9: 208-221

Freund A, Jolivel V, Durand S, Kersual N, Chalbos D, Chavey C, Vignon F, Lazennec G (2004) Mechanisms underlying differential expression of interleukin-8 in breast cancer cells. Oncogene 23: 6105-6114

Haagensen CD (1956) Inflammatory carcinoma. In Diseases of the Breast, Haagensen CD (ed) pp 488-498. Philadelphia: W.B. Saunders

Holloway JN, Murthy S, El Ashry D (2004) A cytoplasmic substrate of mitogen-activated protein kinase is responsible for estrogen receptor-a down-regulation in breast cancer cells: the role of nuclear factor- $\kappa \mathrm{B} . \mathrm{Mol}$ Endocrinol 18: $1396-1410$

Jordan VC (2004) Selective estrogen receptor modulation: concepts and consequences in cancer. Cancer Cell 5: 207-213

Kalaitzidis D, Gilmore T (2005) Transcription factor cross-talk: the estrogen receptor and NF-kappaB. Trends Endocrinol Metab 16: 46-52

Key TJ, Verkasalo PK, Banks E (2001) Epidemiology of breast cancer. Lancet Oncol 2: 133-140

Kleer CG, Van Golen KL, Merajver SD (2000) Review molecular biology of breast cancer metastasis: inflammatory breast cancer: clinical syndrome and molecular determinants. Breast Cancer Res 2: 423-429

Kleer CG, Zhang Y, Pan Q, Gallagher G, Wu M, Wu ZF, Merajver SD (2004) WISP3 and RhoC guanosine triphosphatase cooperate in the development of inflammatory breast cancer. Breast Cancer Res 6: R110-R115

Lerebours F, Bieche I, Lidereau R (2005) Update on inflammatory breast cancer. Breast Cancer Res 7: 52-55

Livak KJ, Schmittgen TD (2001) Analysis of relative gene expression data using real-time quantitative PCR and the 2(-Delta Delta C(T)) Method Methods 25: $402-408$

Low JA, Berman AW, Steinberg SM, Danforth DN, Lippman ME, Swain SM (2004) Long-term follow-up for locally advanced and inflammatory breast cancer patients treated with multimodality therapy. J Clin Oncol 22: $4067-4074$
Nakshatri H, Bhat-Nakshatri P, Martin DA, Goulet RJ, Sledge GW (1997) Constitutive activation of NF-kappaB during progression of breast cancer to hormone-independent growth. Mol Cell Biol 17: $3629-3639$

Nielsen TO, Hsu FD, Jensen K, Cheang M, Karaca G, Hu Z, HernandezBoussard T, Livasy C, Cowan D, Dressler L, Akslen LA, Ragaz J, Gown AM, Gilks CB, van de Rijn M, Perou CM (2004) Immunohistochemical and clinical characterization of the basal-like subtype of invasive breast carcinoma. Clin Cancer Res 10: $5367-5374$

Oh AS, Lorant LA, Holloway JN, Miller DL, Kern FG, El-Ashry D (2001) Hyperactivation of MAPK induces loss of ERa expression in breast cancer cells. Mol Endocrinol 15: 1344-1359

Pratt MA, Bishop TE, White D, Yasvinski G, Menard M, Niu MY, Clarke R (2003) Estrogen withdrawal-induced NF-kappaB activity and Bcl-3 expression in breast cancer cells: roles in growth and hormone independence. Mol Cell Biol 23: 6887-6900

Perou CM, Sorlie T, Eisen MB, van de Rijn M, Jeffrey SS, Rees CA, Pollack JR, Ross DT, Johnsen H, Akslen LA, Fluge O, Pergamenschikov A, Williams C, Zhu SX, Lonning PE, Borresen-Dale AL, Brown PO, Botstein D (2000) Molecular portraits of human breast tumours. Nature 406: $747-752$

Singletary SE, Allred C, Ashley P, Bassett LW, Berry D, Bland KI, Borgen PI, Clark G, Edge SB, Hayes DF, Hughes LL, Hutter RV, Morrow M, Page DL, Recht A, Theriault RL, Thor A, Weaver DL, Wieand HS, Greene FL (2002) Revision of the American joint committee on cancer staging system for breast cancer. J Clin Oncol 17: 3628-3636

Sotiriou C, Neo SY, McShane LM, Korn EL, Long PM, Jazaeri A, Martiat P, Fox SB, Harris AL, Liu ET (2003) Breast cancer classification and prognosis based on gene expression profiles from a population-based study. Proc Natl Acad Sci USA 100: 10393-10398

Stein B, Yang MX (1995) Repression of the interleukin-6 promoter by estrogen receptor is mediated by NF-kappa B and C/EBP beta. Mol Cell Biol 15: 4971 - 4979

Van den Eynden GG, Van der Auwera I, Van Laere S, Colpaert CG, van Dam P, Merajver S, Kleer CG, Harris AL, Van Marck EA, Dirix LY, Vermeulen PB (2004) Validation of a tissue microarray to study differential protein expression in inflammatory and non-inflammatory breast cancer. Breast Cancer Res Treat 85: 13-22

Van der Auwera I, Van Laere SJ, Van den Eynden GG, Benoy I, van Dam P, Colpaert CG, Fox SB, Turley H, Harris AL, Van Marck EA, Vermeulen $\mathrm{PB}$, Dirix LY (2004) Increased angiogenesis and lymphangiogenesis in inflammatory versus noninflammatory breast cancer by real-time reverse transcriptase-PCR gene expression quantification. Clin Cancer Res 10: $7965-7971$

van Golen KL, Davies S, Wu ZF, Wang Y, Bucana CD, Root H, Chandrasekharappa S, Strawderman M, Ethier SP, Merajver SD (1999) A novel putative low-affinity insulin-like growth factor binding protein, LIBC (lost in inflammatory breast cancer), and RhoC GTPase correlate with the inflammatory breast cancer phenotype. Clin Cancer Res 5: $2511-2519$

Van Golen KL, Wu ZF, Qiao XT, Bao L, Merajver SD (2000) RhoC GTPase overexpression modulates induction of angiogenic factors in breast cells. Neoplasia 2: $418-425$

Van Golen KL, Bao LW, Pan Q, Miller FR, Wu ZF, Merajver SD (2002) Mitogen activated protein kinase pathway is involved in RhoC GTPase induced motility, invasion and angiogenesis in inflammatory breast cancer. Clin Exp Metast 19: 301-311

Van Golen KL (2003) Review inflammatory breast cancer: relationship between growth factor signaling and motility in aggressive cancers. Breast Cancer Res 5: 174-179

Van Laere S, Van der Auwera I, Van den Eynden GG, Fox SB, Bianchi F, Harris AL, van Dam P, Van Marck EA, Vermeulen PB, Dirix LY (2005) 
NF-кB/ER crosstalk in inflammatory breast cancer

S) Van Laere et al

Distinct molecular signature of inflammatory breast cancer by cDNA microarray analysis. Breast Cancer Res Treat 93: 237-246

Van Laere SJ, Van den Eynden GG, Van der Auwera I, Vandenberghe M, van Dam P, Van Marck EA, van Golen KL, Vermeulen PB, Dirix LY (2006a) Identification of cell-of-origin breast tumor subtypes in inflammatory breast cancer by gene expression profiling. Breast Cancer Res Treat 95: 243-255

Van Laere SJ, Van der Auwera I, Van den Eynden GG, Elst HJ, Weyler J, Harris AL, van Dam P, Van Marck EA, Vermeulen PB, Dirix LY (2006b)
Nuclear factor-kappaB signature of inflammatory breast cancer by cDNA microarray validated by quantitative real-time reverse transcriptionPCR, immunohistochemistry, and nuclear factor-kappaB DNA-binding. Clin Cancer Res 12: $3249-3256$

Zhou Y, Eppenberger-Castori S, Marx C, Yau C, Scott GK, Eppenberger U, Benz CC (2005) Activation of nuclear factor-kappaB (NFkappaB) identifies a high-risk subset of hormone-dependent breast cancers. Int J Biochem Cell Biol 37: 1130-1144 